\title{
Benefit-Cost and Energy Efficiency Index to Support the Screening of Hybrid Cyclic Steam Stimulation Methods
}

\author{
Laura Osma $^{1}$, Luis García ${ }^{1}$, Romel Pérez ${ }^{2, *}$, Carolina Barbosa ${ }^{1}$, Jesús Botett ${ }^{1}$, Jorge Sandoval ${ }^{2}$ \\ and Eduardo Manrique ${ }^{2}$ \\ 1 Petroleum Engineer School, Universidad Industrial de Santander, Bucaramanga 680002, Colombia; \\ lyosmari@uis.edu.co (L.O.); legarrod@uis.edu.co (L.G.); cbarbogo@uis.edu.co (C.B.); \\ jbottetc@uis.edu.co (J.B.) \\ 2 Instituto Colombiano del Petróleo/Ecopetrol, Piedecuesta 681011, Colombia; \\ Jorge.sandoval@ecopetrol.com.co (J.S.); eduardo.manrique@ecopetrol.com.co (E.M.) \\ * Correspondence: romel.perez@ecopetrol.com.co
}

Received: 10 July 2019; Accepted: 25 September 2019; Published: 6 December 2019

\begin{abstract}
Most of the evaluations of thermal enhanced oil recovery (EOR) methods in numerical simulations mainly focus on the identification of recovery processes with the greatest potential to increase oil recovery. In some cases, the economic aspects of the EOR methods evaluated are also considered. However, these studies often lack the evaluation of the energy efficiency of the proposed methods as a strategy to support the selection of profitable recovery processes. Therefore, this study aimed to identify the potential of different hybrid cyclic steam stimulation (CSS, with flue gas, foam, nanoparticles, or solvents) methods based on a numerical simulation study using a radial model representative of a large heavy oil reservoir in the Middle Magdalena Basin, Colombia. The simulation results were used to estimate the benefit-cost $(\mathrm{B} / \mathrm{C})$ ratios and energy efficiency (EE) indices that can be used to screen and rank the hybrid CSS methods studied. When comparing different hybrid methods, it was found that CSS with nanoparticles or solvents performed better during the first two steam cycles (higher oil saturations). However, CSS with foam and flue gases showed higher incremental oil production ( $\geq 3564$ bbls or $567 \mathrm{~m}^{3}$ ) during the sixth steam cycle. Based on an energy cost index $(\mathrm{ECI}=[(\mathrm{B} / \mathrm{C}) / \mathrm{EE}]), \mathrm{CSS}$ with foam outperformed $(\mathrm{ECI} \approx 453)$ cyclic steam injection with flue gases $(\mathrm{ECI} \approx 21)$ and solvents $(\mathrm{ECI} \approx 0.1)$ evaluated during the sixth steam cycle. The results show that this methodology can be used to guide decision-making to identify hybrid CSS methods that can increase oil recovery in a cost-effective manner and provide an efficient energy balance.
\end{abstract}

Keywords: enhanced oil recovery; thermal methods; cyclic steam stimulation; cyclic steam injection; hybrid technologies; numerical simulation; energy balance; benefit-to-cost ratio

\section{Introduction}

Steam injection is a widely used oil recovery method that has been successfully implemented in heavy, extraheavy, and tar sand reservoirs worldwide [1]. However, in recent years, most steam-based processes (e.g., cyclic or continuous steam injection and steam-assisted gravity drainage (SAGD)) have faced multiple challenges due to a low oil price environment, energy efficiency, and the growing interest in or competition from different energy sources (e.g., lighter crude oils and natural gas). For example, oil production coming from steam injection projects can be considered marginal compared with those coming from unconventional resources in the United States [1-3]. Nevertheless, steam injection methods are still relevant in regions holding important heavy oil, extraheavy oil, and tar sand reserves in countries such as Canada, China, Colombia, Russia, and Venezuela. 
Currently, an important number of cyclic steam stimulation (CSS) projects are approaching a mature stage, including multiple wells with 10 or more steam cycles. At this late stage, the most common approach is to convert CSS projects into continuous steam injection (CSI). However, in other instances, operators and research institutions evaluate options to extend the production life of wells under CSS for diverse reasons (e.g., volatility of oil prices, operators facing uncertainties associated with lease extensions, lack of natural gas for steam generation, etc.). In such cases, hybrid methods have become an alternative to improve oil recovery production in mature wells under CSS. Proposed hybrid CSS methods include steam injection combined with solvents, gases, chemicals (e.g., foams), or nanoparticles, among others [1,4-6].

Regarding the status of thermal enhanced oil recovery (EOR) processes in Colombia, steam injection, specifically, CSS, represents the most relevant production method of heavy crude oil reservoirs in the country [7-10]. Despite some field experiences with hybrid CSS in Colombia [11], the evaluation (from the lab to numerical simulation) and the interpretation of hybrid CSS is a challenge. However, the maturity level of CSS wells varies from one field to another. Therefore, there is a need to understand the timing to evaluate and implement the potential of hybrid CSS methods.

The evaluation of hybrid CSS technologies in Colombia is part of a broader research program that includes heat management strategies and energy sources (e.g., solar) to generate heat or steam. Perez et al. recently documented the preliminary results of this research program, describing the technologies evaluated and the potential of different hybrid CSS methods [12]. This study was based on a comprehensive literature review, interactions with technology providers, and a numerical simulation study using a representative radial model of a CCS well in the Middle Magdalena Basin (MMB). The main results of this study are summarized below:

- Solar energy is the renewable energy source with the largest potential for steam generation in some regions with high enough direct normal irradiation (DNI).

- Downhole heating technologies (including steam recirculation) show the greatest potential before starting CSS.

- Some limitations were identified during the simulation of hybrid CSS methods. Examples include

- Trapped gas and hysteresis effects during CSS with gas (e.g., flue gas, $\mathrm{CO}_{2}$, or $\mathrm{N}_{2}$ ).

- Solvent: crude oil interactions and the interpretation of oil recovery mechanisms injecting mixtures of propane:butane (CSS with solvents).

- $\quad$ Representation of crude oil in situ upgrading during CSS with nanoparticles.

- Hybrid CSS with nanoparticles or solvents performed best at early stages of CSS (second to fourth cycles). In contrast, hybrid CSS with foams or flue gas improved oil recovery at later stages of CSS (sixth cycle or higher).

Based on the uncertainties associated with the numerical simulation of hybrid CSS processes and the incremental oil recoveries observed at different stages of the different hybrid methods evaluated, it is necessary to develop alternative strategies to screen and rank these hybrid steam injection processes. Therefore, this study aimed to evaluate the basic benefit-cost $(\mathrm{B} / \mathrm{C})$ and energy balance indices as possible criteria to support the selection of technologies in terms of economic and energy efficiency indicators. The importance of this study is that it identifies potential development strategies to extend the production life of mature wells under CSS in a cost-effective and energy-efficient manner until the requirements are met for converting CSS projects to CSI for different Colombian assets. Additionally, the evaluation of hybrid CSS provides key information on the feasibility of using these technologies during steam flooding (SF) stages.

\section{Methodology}

The approach to develop the screening and ranking of hybrid CSS methods followed three steps: numerical simulation and the calculation of the $\mathrm{B} / \mathrm{C}$ ratio and the energy efficiency index. 
A radial numerical model was built using a commercial thermal simulator (CMG-Stars). The model included a total of 9400 grid-blocks (" $r$ " $=20$, "theta" divisions $=5$, and $z=94$ (Figure 1)). The total area of the model was approximately $20,234 \mathrm{~m}^{2}$ (5 acres). The grid-block size in the " $r$ " direction varied from 0.03 to $20.42 \mathrm{~m}(0.1$ to $67 \mathrm{ft})$, increasing from the well to the external boundary of the model. The thickness of the model was $142.34 \mathrm{~m}(467 \mathrm{ft})$, with a grid size of approximately $1.524 \mathrm{~m}$ $(5 \mathrm{ft})$. The model included one well and it was perforated in the entire vertical interval. Figure 1 and Table 1 show the grid and average reservoir properties of the model used. The fluid section included three components, representing dead oil, gas in solution (Rs $=11.75 \mathrm{~m}^{3}$ of gas $/ \mathrm{m}^{3}$ of oil (65.9 scf/STB) at a $\mathrm{Pb}=4454 \mathrm{KPa}(646 \mathrm{psi}))$, and water. The petrophysical properties used in the model are representative of the sand reservoir under evaluation (MMB), considering only one rock type [12], and the water-oil and liquid-gas relative permeability curves shown in Figure 2. It is worth mentioning that the properties used in this model are representative of the most prolific formation of shallow heavy oil reservoirs within the MMB.

The baseline of the CSS consisted of 12 steam cycles over a period of 10 years. Before steam injection started, the well was operated under primary production for three months. All steam cycles injected $214.63 \mathrm{~m}^{3} /$ day $\left(1350 \mathrm{bbl} /\right.$ day) of cold water equivalent for six days $\left(1287.8 \mathrm{~m}^{3}\right.$, or $8100 \mathrm{bbls}$, of steam per cycle) using a steam quality of $60 \%$ and an injection temperature of $271.1^{\circ} \mathrm{C}\left(520^{\circ} \mathrm{F}\right)$. The soaking period was for 3 days before the well was reopen for production. The well continued producing until oil production reached the baseline of cold production. At this point, a new steam cycle started [12].
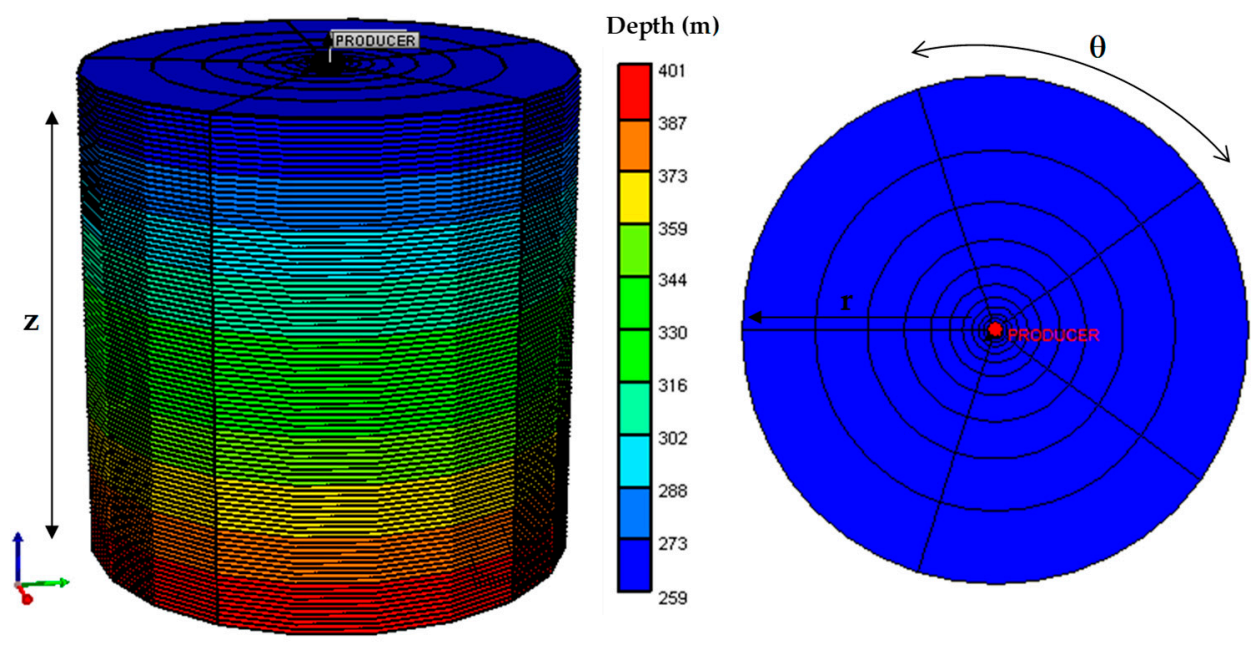

Figure 1. Radial model used to evaluate cyclic steam stimulation (CSS) and hybrid CSS.

Table 1. Average reservoir properties.

\begin{tabular}{cc}
\hline Variable & Value \\
\hline Porosity (Fraction) & 0.23 \\
Permeability (Darcy) & 1.17 \\
Vertical-to-horizontal permeability ratio- $-\mathrm{K}_{\mathrm{v}} / \mathrm{K}_{\mathrm{h}}$ (Fraction) & 0.3 \\
Depth $(\mathrm{m})$ & $259-401$ \\
Initial pressure $(\mathrm{KPa})$ & 4619.5 \\
Initial temperature $\left({ }^{\circ} \mathrm{C}\right)$ & 40.55 \\
Oil gravity ( ${ }^{\circ} \mathrm{API} @$ standard conditions) & 12 \\
Oil viscosity (cP @ standard conditions) & 44,475 \\
OOIP $\left(\mathrm{m}^{3}\right)$ & 161,685 \\
\hline
\end{tabular}



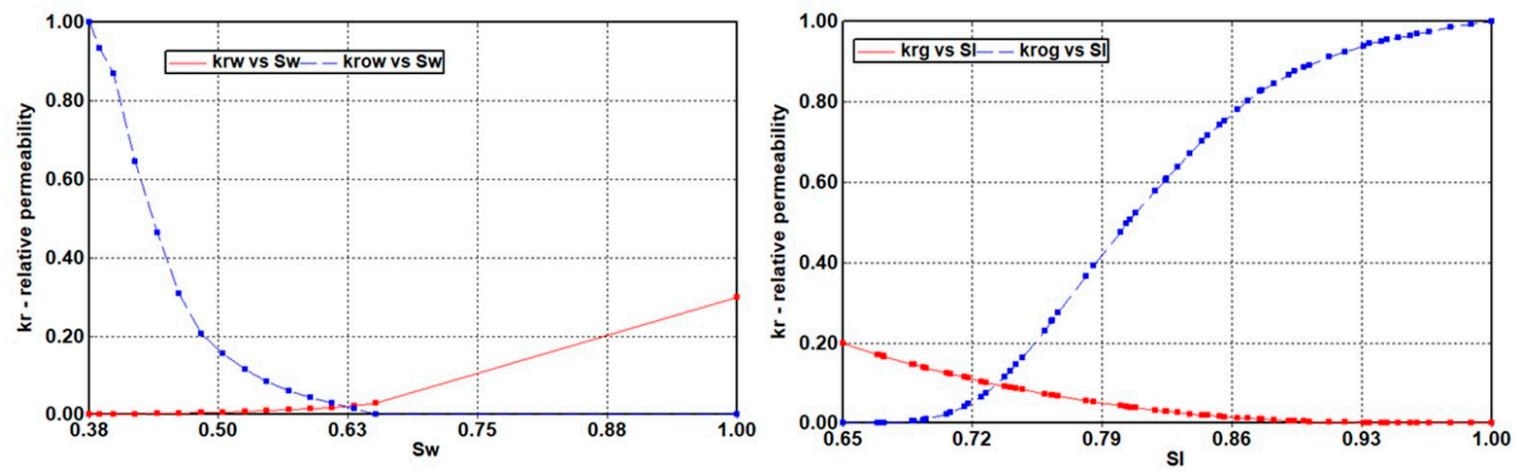

Figure 2. Relative permeability curves: $\mathrm{Kr}$ water-oil and $\mathrm{Kr}$ liquid-gas.

The proposed hybrid CSS methods were tested at different cycles to identify the greatest potential for their implementation. Each hybrid technology incorporated modifications of the fluid model or included some equations and/or reactions to represent the main mechanisms of each of the tested methods. Perez et al. [12] described the followed approach to model the different hybrid CSS methods evaluated. However, the main simulation approach used in this study is summarized below:

- Steam injection (volume and conditions) was the same as that used for the baseline and was kept constant for all hybrid CSS methods tested.

- CSS with foam was modeled using six reactions that simulated the coalescence of foam and its regeneration over time. Four new components were included in the fluid section (surfactant, nitrogen, lamella, and trapped gas). The foam was preformed with nitrogen before its injection. Foam treatment using a surfactant concentration of $0.25 \mathrm{v} / \mathrm{v}$ was injected before the steam cycle. A total of $7 \mathrm{t}$ of surfactant was injected over a period of 3 days.

- In this study, the hybrid CSS with solvent considered the use of liquefied petroleum gas (LPG). The injection was done in batches, starting with a half-day steam batch of $107.2 \mathrm{~m}^{3}$ ( $675 \mathrm{bbls}$ ), followed by the vaporized LPG slug of 138,488 $\mathrm{m}^{3}\left(4,890,672 \mathrm{ft}^{3}\right)$, and finishing with a second and final steam batch of $1180.6 \mathrm{~m}^{3}$ (7425 bbls).

- CSS with flue gas was performed under immiscible conditions (no oil-flue-gas interaction). Molar gas composition was $83 \% \mathrm{~N}_{2}$ and $17 \% \mathrm{CO}_{2}$. The injection scheme used in this study consisted of 3 days of flue gas injection at $141,584 \mathrm{Sm}^{3} /$ day $\left(5 \mathrm{MM} \mathrm{Sft}^{3} /\right.$ day), followed by the steam cycle.

- Hybrid CSS with nanoparticles was based on laboratory data documented in the literature. The main modeling mechanism was the in situ upgrading (oil viscosity reduction reaction due to the interaction of the crude oil and the nanoparticles). Simulation parameters included the activation energy $\left(13,715,728 \mathrm{~J} / \mathrm{mol}\right.$, or 13,000 BTU/mol), frequency factor $\left(1.8\right.$ day $\left.^{-1}\right)$, cracking temperature $\left(210^{\circ} \mathrm{C}\right.$, or $\left.410^{\circ} \mathrm{F}\right)$, improved oil density $\left(928.59 \mathrm{~kg} / \mathrm{m}^{3}\right.$, or $\left.57.97 \mathrm{lb} / \mathrm{ft}^{3}\right)$, and molecular weight of the upgraded oil $(243 \mathrm{~kg} / \mathrm{kgmol}$, or $243 \mathrm{lb} / \mathrm{lbmol})$. A viscosity reduction of $70 \%$ was assumed in this study, as reported by Perez et al. [12].

As stated earlier, the performance of different hybrid CSS methods was evaluated in different steam cycles. However, in this study, the results of CSS with foams, solvents, and flue gas were compared in the sixth steam cycle. These hybrid CSS methods were compared according to the incremental oil with respect to CSS (baseline), the B/C ratio, and the energy efficiency index. For the case of hybrid CSS with nanoparticles, the results presented only include the incremental oil during the second cycle and a preliminary estimate of the $\mathrm{B} / \mathrm{C}$ ratio. It is important to mention that this technology is still at early stages of development and the information available at lab or field scale is limited.

The simplified $\mathrm{B} / \mathrm{C}$ ratio was calculated using the following equation:

$$
\mathrm{B} / \mathrm{C}=(\text { Incomes }) /(\text { Expenses }+ \text { OPEX })
$$


where

$$
\begin{aligned}
& \text { Incomes }=[(\text { Incremental oil } \times(1 \text {-Royalties })] \times(\text { Oil price }- \text { Deductions }) \\
& \text { Expenses }=(\text { Incremental oil } \times \text { lifting costs })+\text { Cost of the required energy } \\
& \text { Operational expenditures }(\mathrm{OPEX})=\text { Supplies }+ \text { Equipment. }
\end{aligned}
$$

It is important to mention that this simplified economic analysis has the purpose of quick screening of hybrid CSS methods and it is based on the fact that the proposed hybrid CSS pilots do not require investments related to surface facilities or steam generators. In that sense, there is no consideration of capital expenditures (CAPEX) because the fields under evaluation already have had all the equipment operating for a decade or more. Hence, to estimate a simplified cash flow of the proposed hybrid methods, only the costs associated with the purchase of products (e.g., gas, nanoparticles, solvent, and surfactants) and rental of possible equipment needed to inject it (e.g., nitrogen for gas injection or foam generation) are required. On the other hand, steam cycles in the later stages of CSS are generally short (injection of one to two weeks and production periods of a few months to a year) and do not require use of the discounted cash flow or net present value (NPV) calculations typically used in continuous steam injection processes (CSI or SAGD).

In this study, crude oil price deductions included discounts for oil quality and transportation (Table 2). Supplies included the cost of additives (e.g., flue gas, nanoparticles, solvents, and surfactants), while the equipment costs were those required for each of the technologies evaluated. Table 2 summarizes the main variables used for the estimation of the $\mathrm{B} / \mathrm{C}$ ratio.

Table 2. Variables used to estimate the benefit-cost (B/C) ratio.

\begin{tabular}{cc}
\cline { 2 - 3 } Variable & Value \\
\cline { 2 - 3 } Oil price (US\$/bbl) ${ }^{1}$ & 50 \\
Oil quality deduction (US\$/bbl) & 7.08 \\
Oil transport deduction $(\mathrm{US} \$ / \mathrm{bbl})$ & 2.84 \\
Lifting costs $(\mathrm{US} \$ / \mathrm{bbl})$ & 13.2 \\
Cost of energy (US\$ $/ \mathrm{MMBTU})^{2}$ & 7.05 \\
Tax deduction $(\%)$ & 33 \\
Royalties $(\%)$ & 8 \\
\hline
\end{tabular}

The final step of the methodology was to estimate the energy efficiency of the CSS (base case) and hybrid CSS methods evaluated. This study used British thermal units (BTUs) as the energy unit to compare energy sources or fuels on an equal basis, as proposed by the U.S. Energy Information Administration (EIA) [13]. The energy efficiency (EE) index is an energy balance represented by the relationship between the required energy and the energy produced in each steam cycle (CSS or hybrid CSS):

$$
\mathrm{EE}=\text { Required Energy/Produced Energy. }
$$

$\mathrm{EE}$ index values below one $(\mathrm{EE}<1)$ indicate that the process is energy efficient, producing more energy (e.g., oil) than the required energy (e.g., steam, additives, equipment, etc.). For EE $\geq 1$, the process is energy inefficient and represents methods that produce less energy (oil) than the required energy injected.

The $\mathrm{B} / \mathrm{C}$ ratio and $\mathrm{EE}$ index can be used independently or combined as a screening criterion to select and rank hybrid CSS methods. When combining both variables, an energy cost index (ECI) can be defined as

$$
\mathrm{ECI}=(\mathrm{B} / \mathrm{C}) / \mathrm{EE}
$$


The use of this indicator (ECI) can guide the decision-making to identify hybrid CSS methods that can increase oil recovery profitably with an efficient energy balance. Hence, this study evaluated the proposed indices to support the selection of hybrid CSS technologies using a numerical model representative of a large heavy oil field of the Middle Magdalena Basin.

Finally, it is important to mention that the increases in oil recoveries, expenses, and OPEX reported in this study are incrementally related to each of the hybrid CSS technologies evaluated with respect to the base case (CSS). Therefore, the $\mathrm{B} / \mathrm{C}$ ratios and $\mathrm{EE}$ indices presented in this paper are based on the increment generated by each of the hybrid CSS technologies.

\section{Results}

Before presenting and discussing the results of the evaluated hybrid CSS method, it is important to summarize the results of the base case of CSS. The base case simulation included the injection of 12 steam cycles as described in the methodology. For each cycle, the well kept producing at a variable rate but constrained up to $95.4 \mathrm{~m}^{3} /$ day (600 stock tank liquid per day, or STL/day) until oil production reached the baseline of cold production (solid blue line in Figure 3). At this point, a new steam cycle began.

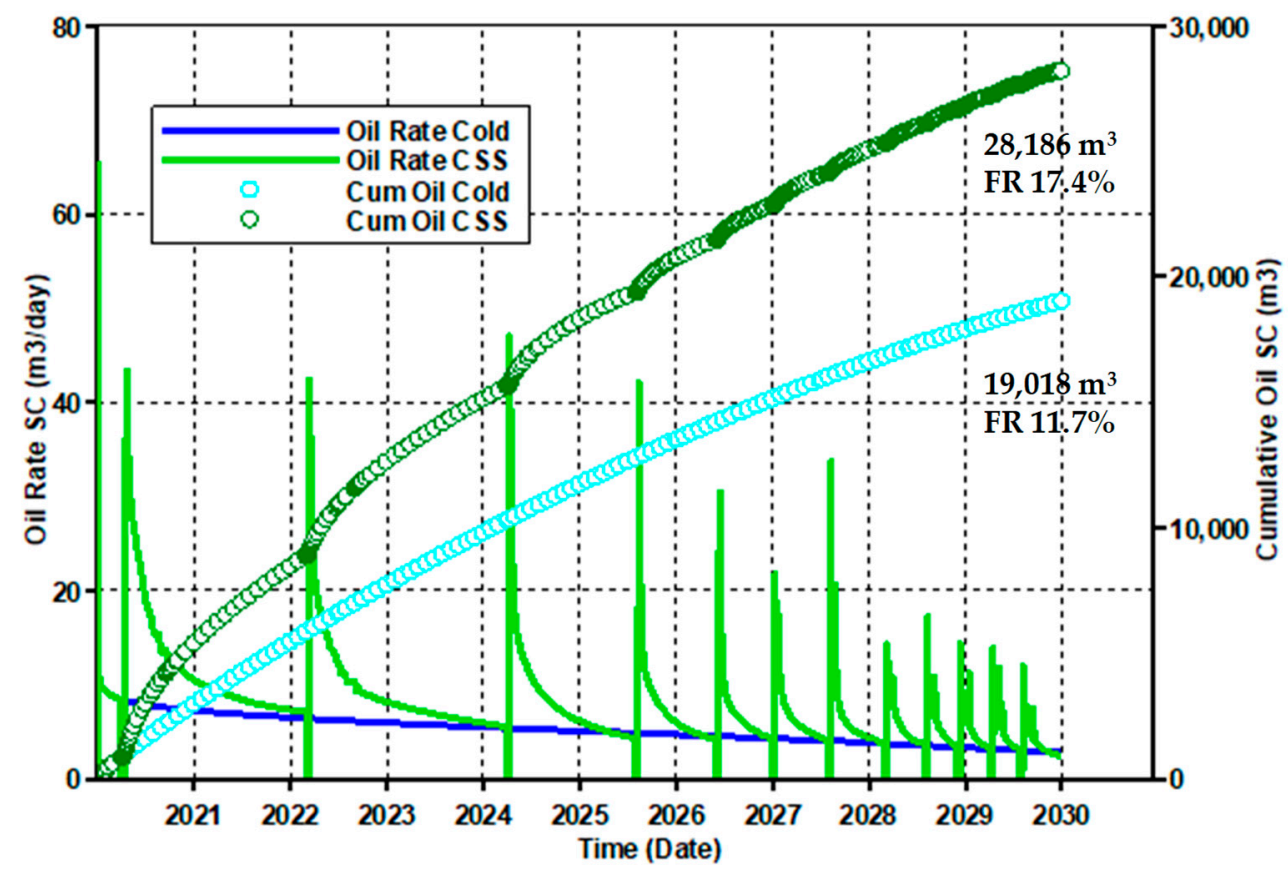

Figure 3. CSS performance prediction of the 12 steam cycles in the radial model used in this study.

It is important to mention that the model reasonably represents the average performance of the CSS wells in the field under evaluation (Figure 3). Most of the incremental production is coming from the first cycles, which last up to two years. In this particular example, approximately $60 \%$ of the total incremental oil was produced $\left(5588 \mathrm{~m}^{3}\right)$ during the first 2 of the 12 steam cycles. However, after the seventh steam cycle, the efficiency decreased drastically 4 months after steam injection started. The incremental oil recovery obtained from CSS was approximately $6 \%\left(9168 \mathrm{~m}^{3}\right.$, or $\left.57,668 \mathrm{bbls}\right)$ and had a cumulative steam/oil ratio (CSOR) of $0.54 \mathrm{~m}^{3} / \mathrm{m}^{3}$. Incremental oil recovery factors were below the range of international standards documented for CSS projects $(10 \%-40 \%)[4,6]$. These low oil recovery factors can be attributed to the low steam quality injected, the heat losses from the wellhead to the formation, the design of the steam cycle, and the operating conditions, among others. However, the optimization of CSS was not part of this investigation.

Table 3 summarizes the information obtained from the numerical model for the second and sixth steam cycles and the financial data based on the average cost structure of steam injection operations 
in Colombia. For example, the energy conversion for the natural gas used in the CSS in the Middle Magdalena Basin was $36.81 \mathrm{MJ} / \mathrm{m}^{3}$ of natural gas (988 BTU/ $\mathrm{ft}^{3}$ ), representing 5.22 TJ (4946 MMBTU) injected per cycle (Table 3). It is important to mention that all the energy data presented in this paper were estimated at surface conditions. However, the numerical model considered all heat losses from the steam generator to the wellbore and reservoir rock based on bottom-hole injection pressure, temperature, and steam quality. The heat losses estimated in this simulation study were approximately $50 \%$, which agrees with that reported in the literature [14]. Figure 4 shows the effective energy delivered to the reservoir in each of the 12 steam cycles simulated in this study.

Table 3. Summary of production and financial data for early and intermediate steam cycles.

\begin{tabular}{ccc}
\hline Parameter & $\begin{array}{c}\text { Early Stages } \\
\text { (Second Cycle) }\end{array}$ & $\begin{array}{c}\text { Intermediate Stage } \\
\text { (Sixth Cycle) }\end{array}$ \\
\hline Incremental Oil Production (bbls) $\left(\mathrm{m}^{3}\right)$ & $(14,479) 2301$ & $(2591) 411.9$ \\
Production Associated with Royalties $(\mathrm{bbls})\left(\mathrm{m}^{3}\right)$ & $(1158) 184.1$ & $(207) 32.9$ \\
Net Incremental Production (bbls) $\left(\mathrm{m}^{3}\right)$ & $(13,321) 2117$ & $(2384) 379$ \\
Net Incomes (US\$) & 533,906 & 95,551 \\
Lifting Cost (US\$) & 191,123 & 34,201 \\
Required Energy (MMBTU) & 4946 & 4946 \\
Cost of Energy Required (US\$) & 34,869 & 34,869 \\
Expenses (US\$) & 225,992 & 69,070 \\
B/C Ratio & 2.36 & 1.38 \\
\hline
\end{tabular}

${ }^{1}$ BTU equivalent of steam injected per cycle (5.22 TJ).

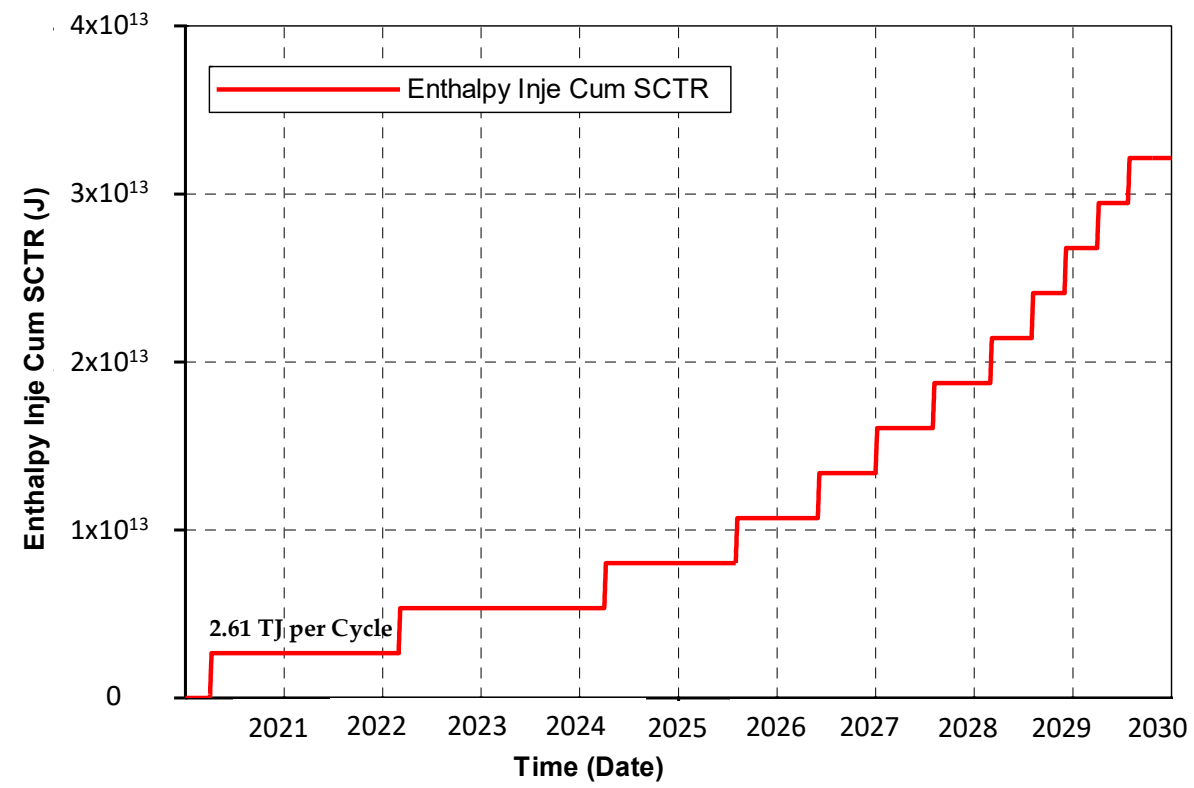

Figure 4. Cumulative injected energy during the 12 simulated steam injection cycles.

Figure 5 shows the cash flow and the EE index (Equation (5)) per steam cycle injected. As expected, at a fixed oil price of US $\$ 50$ per barrel, the economics of CSS was marginal after the 7th steam cycle, and the EE index started to approach energy inefficiency after the 10th cycle if the CSS is was optimized over time, regardless of the oil price. The cash flow plotted in Figure 5 represents the difference between the net incomes and the expenses per steam cycle. 


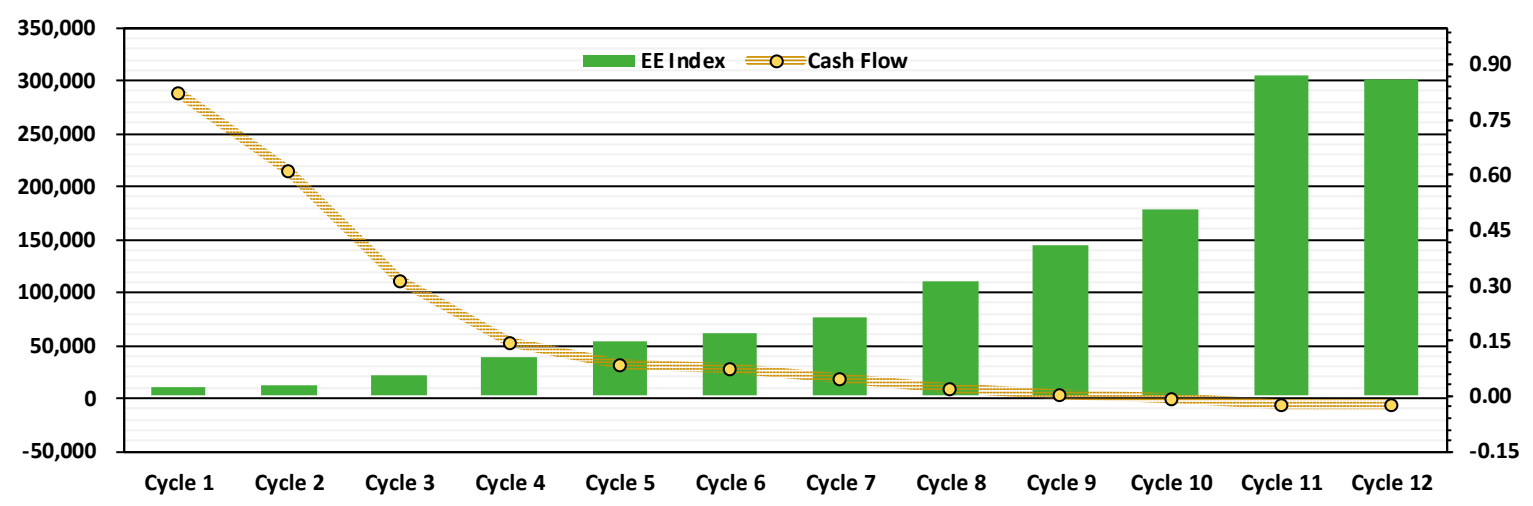

Figure 5. Cash flow and energy efficiency (EE) index per steam cycle obtained from the simulation study.

\subsection{Hybrid CSS Methods}

As the number of steam cycles increases, the oil recovery efficiency of CSS decreases considerably. At these later stages of CSS, a common approach is to turn the project into a CSI or SF [14]. However, in cases where conversion to SF is not technically or economically viable, an option for extending the production life of wells under CSS is to use hybrid CSS methods [4-6]. In this study, four hybrid CSS methods were evaluated at a numerical simulation scale, specifically, CSS combined with flue gas, foams, nanoparticles, or solvents (LPG). The simulation results were compared based on the incremental oil recovery, the $\mathrm{B} / \mathrm{C}$ ratio, and the energy balance (EE and $\mathrm{ECI}$ ) indices in order to rank the hybrid CSS methods studied.

\subsubsection{CSS with Nanoparticles}

The use of nanoparticles for EOR applications has generated an increasing amount of interest in the oil and gas industry. However, this technology can be considered relatively new, and large field applications have not been documented in the literature [15]. Druetta et al. reported a comprehensive review of the application of nanotechnology in EOR [16]. However, this research also recognized that there are some limitations of the technology that must be addressed. The use of nanoparticles to generate physical and chemical changes due to their interaction with heavy crude oils has been widely proposed. Heat transfer improvement and viscosity reduction (e.g., breakage of $\mathrm{C}-\mathrm{S}$ bonds and hydrogenation of unsaturated bonds) are among the proposed mechanisms during the interaction of crude oil and nanoparticles [16-23].

Despite the multiple mechanisms attributed to the effects of nanoparticles during steam injection, in this study, the reduction of oil viscosity (in situ upgrading) was selected as the main mechanism for this hybrid CSS method [12,24-27]. Crude oil viscosity reduction from $60 \%$ to $80 \%$ of the original reservoir oil has been reported in different laboratory studies [12,25-29]. In this study, a 70\% viscosity reduction was defined based on the study reported by Yi et al. [26]. This reduction in viscosity was assumed using nickel oxide $(\mathrm{NiO})$ nanoparticles due to their catalytic effects during aquathermolysis reactions reported during CSS experiments [26].

According to the numerical simulation studies conducted in this research, CSS with nanoparticles showed better effects in the early stages of steam injection [12]. Therefore, this hybrid method was evaluated during the second steam cycle. Figure 6 shows the simulation results of the first two steam cycles with nanoparticles compared to cold production and conventional CSS.

Table 4 shows the incremental oil recovery $\left(1743 \mathrm{~m}^{3}\right.$, or $\left.10,963 \mathrm{bbls}\right)$ compared to the second cycle of CSS (Table 3) and the financial parameters to calculate the B/C ratio (0.15) of this technology. In this example, the injection of nanoparticles $(\approx 2000 \mathrm{ppm}$, or $0.20 \mathrm{wt} \%)$ was coinjected with the steam stream [12]. Hence, there was no additional energy required to inject the nanoparticles. The cost of nanoparticles was obtained from Sigma-Aldrich [30]. 


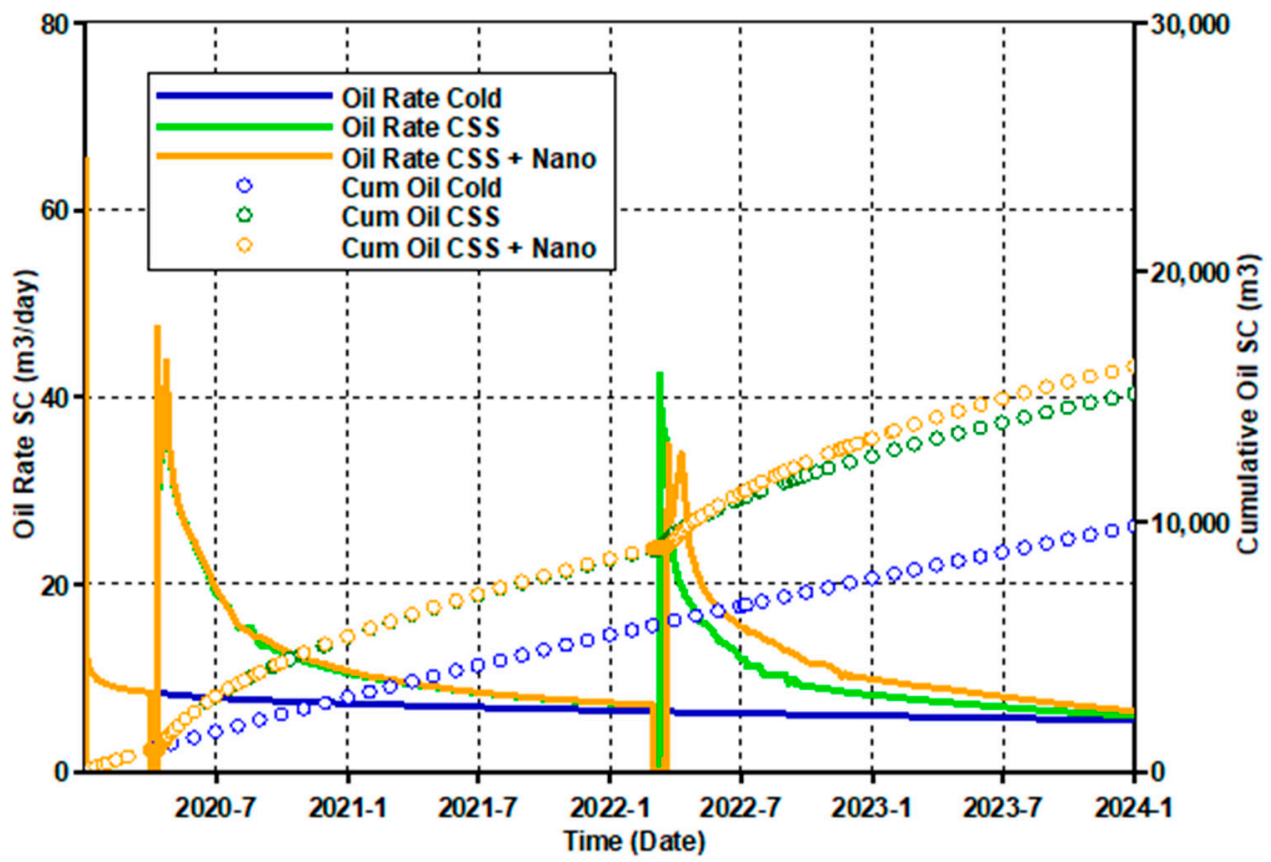

Figure 6. Performance prediction of CSS with nanoparticles during the first two cycles.

Table 4. Summary results to estimate the B/C ratio for the hybrid CSS with nanoparticles evaluated during the second steam cycle.

\begin{tabular}{|c|c|}
\hline Parameter & $\begin{array}{l}\text { Early Stages } \\
\text { (Second Cycle) }\end{array}$ \\
\hline Incremental Oil Production, bbls, $\left(\mathrm{m}^{3}\right)$ & $10,963(1743)$ \\
\hline Production Associated with Royalties, bbls, $\left(\mathrm{m}^{3}\right)$ & $877(139)$ \\
\hline Net Incremental Production, bbls, $\left(\mathrm{m}^{3}\right)$ & $10,086(1604)$ \\
\hline Net Incomes (US\$) ${ }^{1}$ & 404,247 \\
\hline Lifting Cost (US\$) & 144,712 \\
\hline Mass of Nanoparticles Injected, $\mathrm{t},(\mathrm{kg})$ & $1.9(1925)$ \\
\hline Nanoparticle Cost (US\$) ${ }^{2}$ & $2,598,750$ \\
\hline Injection Costs (US\$) ${ }^{3}$ & 8000 \\
\hline Expenses (US\$) & 144,712 \\
\hline Operational Expenditures (OPEX) (US\$) & $2,606,708$ \\
\hline B/C Ratio & 0.15 \\
\hline
\end{tabular}

${ }^{1}$ Same oil price of US\$ 50/bbl was used; ${ }^{2} \mathrm{NiO}$ cost of 1.35 US\$/g was used [27]; ${ }^{3}$ Estimated at US $\$ 1000 /$ day.

Due to the lack of information available for this hybrid CSS method, the EE index was not estimated for this technology. However, the results are further discussed in the next subsection.

\subsubsection{CSS with Foam, LPG, or Flue Gas}

This subsection presents the comparison of the $\mathrm{B} / \mathrm{C}$ ratio and $\mathrm{EE}$ index for different hybrid CSS methods during the sixth steam cycle. Although CSS injection with LPG (solvents in general) performed better in the early stages of the CSS, it was decided to compare this hybrid CSS method during an intermediate cycle, in which the flue gas and foams showed better incremental recoveries [12]. Tables 5 and 6 summarize the results obtained for the different methods evaluated, including the $\mathrm{B} / \mathrm{C}$ ratios and EE indices for each of the hybrid CSS methods, respectively. The injection scheme used for each of these hybrid CSS methods was described in the Methodology section, while the additional information to support the estimation of the proposed EE index is summarized below: 
- $\quad$ CSS with Foam:

- The surfactant injected was a commercial alpha olefin sulfonate (AOS) at a cost of US\$4300/t. To inject $7000 \mathrm{~kg}(7 \mathrm{t})$ of surfactant, a total of $64,279.24 \mathrm{~m}^{3}\left(2.27 \mathrm{MMft}^{3}\right)$ of $\mathrm{N}_{2}$ was required.

- The energy required to inject the foam (surfactant and $\mathrm{N}_{2}$ ) included the fuel (diesel) consumption to generate $\mathrm{N}_{2}\left(1 \mathrm{~m}^{3}\right.$ of diesel for $6238.7 \mathrm{~m}^{3}$ of $\mathrm{N}_{2}$, or 1 gal of diesel for $834 \mathrm{ft}^{3}$ of $\mathrm{N}_{2}$ ). Diesel energy content used was $38,308 \mathrm{MJ} / \mathrm{m}^{3}$ (137,381 BTU/gal).

- $\quad$ CSS with LPG:

- $\quad$ LPG values were representative of a local supplier, with a density of approximately $0.54 \mathrm{~kg} / \mathrm{L}$ ( $1 \mathrm{~L}$ of LPG liquid $\approx 0.273 \mathrm{~m}^{3}$, or $273 \mathrm{~L}$, or $9.64 \mathrm{ft}^{3}$ of LPG gas).

- $\quad$ LPG energy content used was $25,467 \mathrm{MJ} / \mathrm{m}^{3}$ (91,330 BTU/gal).

- $\quad$ CSS with Flue Gas:

- To estimate the energy required in this method, the injection of $\mathrm{N}_{2}$ (1 gal of diesel for $834 \mathrm{ft}^{3}$ of $\mathrm{N}_{2}$ ) was assumed. In this case, the total volume of gas injected was $424,752 \mathrm{~m}^{3}\left(15 \mathrm{MMft}^{3}\right)$ (Table 5).

- The cost of the flue gas (0.1 US\$ per 1000 cubic feet (MCF)) was based on the literature [31].

Table 5. Summary data to estimate the B/C ratios for different hybrid CSS methods evaluated during the sixth steam cycle.

\begin{tabular}{cccc}
\hline Parameter & CSS with Foam & CSS with Solvents & CSS with Flue Gas \\
\hline Incremental Oil Production, bbls, $\left(\mathrm{m}^{3}\right)$ & $13,444(2137)$ & $1088(173)$ & $3564(567)$ \\
Production Associated with Royalties, bbls, $\left(\mathrm{m}^{3}\right)$ & $1076(171)$ & $87(14)$ & $285(45)$ \\
Net Incremental Production, bbls, $\left(\mathrm{m}^{3}\right)$ & $12,368(1966)$ & $1001(159)$ & $3279(522)$ \\
Net Incomes (US\$) & 495,709 & 40,120 & 131,418 \\
Lifting Cost (US\$) & 177,461 & 14,362 & 47,045 \\
Injected Surfactant, t, (kg) & $7(7000)$ & n.a. & n.a. \\
Surfactant Cost (US\$) & 30,100 & n.a. & n.a. \\
Nitrogen Unit Rental Cost (US\$) & $16,365^{1}$ & n.a. & n.a. \\
Volume of LPG Injected, ft ${ }^{3},\left(\mathrm{~m}^{3}\right)$ & n.a. ${ }^{3}$ & $4,890,672(138,488)$ & n.a. \\
LPG Cost (US\$) & n.a. & $232,146^{4}$ & n.a. \\
Costs of Storage Tanks (US\$) & n.a. & 10735 & n.a. \\
Pumping Costs (US\$) & $00^{3}$ & 1000 & 3000 \\
Vol. of Flue Gas Injected, MM ft ${ }^{3},\left(\mathrm{~m}^{3}\right)$ & n.a. & n.a. & 15 (424,752) \\
Cost of Flue Gas (US\$) & n.a. & n.a. & 1500 \\
Expenses (US\$) & 177,461 & 14,362 & 47,045 \\
OPEX (US\$) & 46,465 & 234,146 & 4500 \\
B/C Ratio & 2.21 & 0.16 & 2.55 \\
\hline
\end{tabular}

${ }^{1}$ Quotation from provider; ${ }^{2}$ Not applicable; ${ }^{3}$ Included in the nitrogen unit rental cost; ${ }^{4}$ At a liquefied petroleum gas (LPG) cost of $0.85 \mathrm{US} \$ / G a l ;{ }^{5}$ Includes ISO tank rental and transportation.

Table 6. Summary data to estimate the EE indices for different hybrid CSS methods evaluated during the sixth steam cycle.

\begin{tabular}{|c|c|c|c|}
\hline Parameter & CSS $^{1}$ with Foam & $\operatorname{CSS}^{1}$ with Solvents & CSS $^{1}$ with Flue Gas \\
\hline $\begin{array}{c}\text { Energy required to generate foam, } \\
\text { MMBTU, (TJ) }\end{array}$ & $375^{2}(0.396)$ & n.a. ${ }^{3}$ & n.a. \\
\hline Energy of LPG injected, MMBTU, (TJ) & n.a. & $12,256^{4}(12.937)$ & n.a. \\
\hline $\begin{array}{c}\text { Energy required to inject flue gas, } \\
\text { MMBTU, (TJ) }\end{array}$ & n.a. & n.a. & $2471(2.608)$ \\
\hline Energy produced, MMBTU ${ }^{5},(\mathrm{TJ})$ & $76,927(81.201)$ & $6226(6.572)$ & $20,393(21.526)$ \\
\hline EE index & 0.005 & 1.969 & 0.121 \\
\hline
\end{tabular}

\footnotetext{
${ }^{1}$ Same BTU (TJ) per cycle for all steam cycles (Table 3); ${ }^{2}$ Diesel used to generate the $\mathrm{N}_{2} ;{ }^{3}$ Not applicable;

${ }^{4}$ LPG slug of 134,202 gal injected BTU equivalent; ${ }^{5}$ Incremental oil assuming that 1 barrel of oil equivalent $(\mathrm{BOE})=5.722 \times 10^{6} \mathrm{BTU}(0.006 \mathrm{TJ})$.
} 
The results of the $\mathrm{B} / \mathrm{C}$ ratios calculated for the hybrid CSS methods evaluated during the sixth cycle clearly show the inefficiency of CSS with solvents (Table 5). This hybrid method was more efficient in the early stages of CSS due to higher oil saturations. On the contrary, hybrid CSS with flue gases or foams showed better $\mathrm{B} / \mathrm{C}$ ratios in later stages of the process. Regarding the $\mathrm{EE}$ index (Table 6), the use of solvents was highly inefficient (EE $>1$ ) compared with CCS with foams or flue gases $(\mathrm{EE}<1)$. However, these differences are discussed in the next section.

\section{Discussions}

As stated earlier, approximately $60 \%$ of the total incremental oil was produced $\left(5588 \mathrm{~m}^{3}\right)$ during the first 2 of the 12 steam cycles. Nevertheless, as the injection cycles mature, the steam injection strategy must be adjusted over time to improve the economic and energy efficiency of late steam cycles. Regarding the CSS with nanoparticles, simulation results showed that oil recovery improved during the early steam cycles. These results clearly suggest that the injection of nanoparticles intended to improve oil quality (e.g., reduce oil viscosity in situ) requires higher oil saturations. However, and despite the incremental oil recovery obtained during the second steam cycle (Table 4 ), the low $\mathrm{B} / \mathrm{C}$ ratio was strongly influenced by the cost of the $\mathrm{NiO}$ nanoparticles [30]. While the costs of nanoparticles can improve when the technology reaches a commercial scale, some aspects should be considered when evaluating this hybrid CSS method:

- The strategy to inject a stable stream of steam with dispersed nanoparticles and its propagation through the reservoir has important uncertainties for this recovery process at numerical and field scales.

- The impact of type, size, and concentration of nanoparticles on reservoir permeability needs to be addressed [16]. However, the impact of permeability reduction due to the injection of nanoparticles is expected to be lower during CSS compared with CSI. This is based on the huff-and-puff nature of CSS operations and the high permeability characteristic of heavy oil reservoir candidates to steam injection. It is important to remark that the type, size, and concentration of nanoparticles did not represent a key objective in this simulation study. First and foremost, commercial simulators are not fully capable of simulating the injection, flow, and potential entrapment of nanoparticles. On the other hand, this methodology is intended to provide some insights during screening stages of hybrid CSS technologies. As of today, there is no commercial application that can justify the viability of this hybrid technology given the uncertainties (e.g., injection method, possible filtration effects during the injection and propagation in the reservoir, etc.) associated with this recovery process.

With respect to the efficiency of CSS with LPG (solvents in general), regardless of its performance in the early or later stages of the steam cycle, this recovery process is energy inefficient. The $\mathrm{B} / \mathrm{C}$ ratio and EE index estimated in this study (Tables 5 and 6) were strongly impacted by the remaining oil saturation before the start of the sixth steam cycle. However, the estimation of these variables $(\mathrm{B} / \mathrm{C}$ and EE) excluded important aspects that make this recovery process even more inefficient from the point of view of the energy balance. Some of these aspects includes but are not limited to the following:

- Solvent recovery must be included for the success of this recovery process. This was also addressed by Bayestehparvin et al. [5] based on state-of-the-art solvent-based and solvent-assisted recovery processes.

- If CSS with solvents is developed to precipitate asphaltenes, the benefits of in situ upgrading should be included in the $\mathrm{B} / \mathrm{C}$ ratio calculations (not considered in this study). However, the risk of possible permeability reduction due to asphaltene deposition in the porous media represents another uncertainty of this hybrid CSS method.

- High-oil-price scenarios and high solvent recovery rates will definitively improve the $\mathrm{B} / \mathrm{C}$ ratio of CSS with LPG (solvents). However, the recovery efficiency of the solvent injected and the energy required to separate it (for reutilization purposes) should be considered in the estimation 
of EE indices. This represents important uncertainties that diminish the technical and economic feasibility of this recovery process in Colombian assets.

Based on the level of maturity of the wells evaluated in the Middle Magdalena Basin, the results suggest that hybrid CSS methods with foams or flue gases seem to be the most promising recovery processes to evaluate at pilot scale. Both hybrid methods show promising $\mathrm{B} / \mathrm{C}$ ratios and $\mathrm{EE}$ indices (Tables 5 and 6 , respectively). However, the higher B/C ratio estimated for CSS with flue gases could be influenced by the optimistic costs of the flue gas (0.1 US\$/MCF) [31]. The quality and cost of flue gas depends on the fuel used for steam or power generation (i.e., natural gas, fuel oil, etc.). Therefore, when evaluating the source of flue gases, it is important to consider the potential costs of separating and removing unwanted components (i.e., particulates, $\mathrm{NO}_{\mathrm{x}}$, and $\mathrm{SO}_{\mathrm{x}}$ ), flue gas compression, and transport if the source is not located at the well site (i.e., portable steam generator). Regarding the numerical simulation of CSS with flue gas, some of the effects that need to be evaluated include but are not limited to the following:

- Trapped gas and its possible effects on the hysteresis of relative permeability. The main goal of flue gas injection is to generate the flow diversion due to the trapped gas in lower oil saturation zones saturated with water (condensed steam). However, trapped gas effects can also be influenced by gas segregation due to high vertical communication within the net pay of the reservoir $(\mathrm{Kv} / \mathrm{Kh}>$ 0.3 ) and/or the huff and puff of CSS operations.

- CSS with flue gas (or any other gas) must be carefully designed to avoid high near-wellbore repressurization, which could negatively affect the steam quality at downhole conditions.

Cyclic steam injection with foams represents the CSS hybrid method with the most documented field applications [32,33]. The main objective of foam injection during CSS is to generate a flow diversion that that promotes the injected steam to contact unswept zones in the stimulated well. Despite the number of field implementations, this recovery process still has uncertainties related to the difficulties of upscaling laboratory studies and representing the chemical reactions in numerical simulation models. However, due to its good $\mathrm{B} / \mathrm{C}$ ratio (2.21) and an $\mathrm{EE}$ index well below the unit (0.005), this recovery process is an attractive strategy to optimize late steam cycles. When comparing the ECI of the CSS with the different hybrid CSS methods during the sixth cycle, CSS with foams outperformed all hybrid CSS methods evaluated (Figure 7). The predictions of CSS with foams in the later stages of the steam cycle (during or after the sixth steam cycle) and the results of the proposed methodology contributed to receiving a sanction for a pilot test in two wells of a heavy oil reservoir located in the Middle Magdalena Basin. In addition, the decision to select the field and the well candidates to test this hybrid process was supported by the lessons learned from multiple CSS pilot tests with foams implemented by an international operator in Colombia [11] and the reservoir analogue definition of the Petroleum Resources Management System (PRMS) [34]. Steam and preformed foam injection ended in mid-August 2019. However, its performance is expected to be documented in another publication.

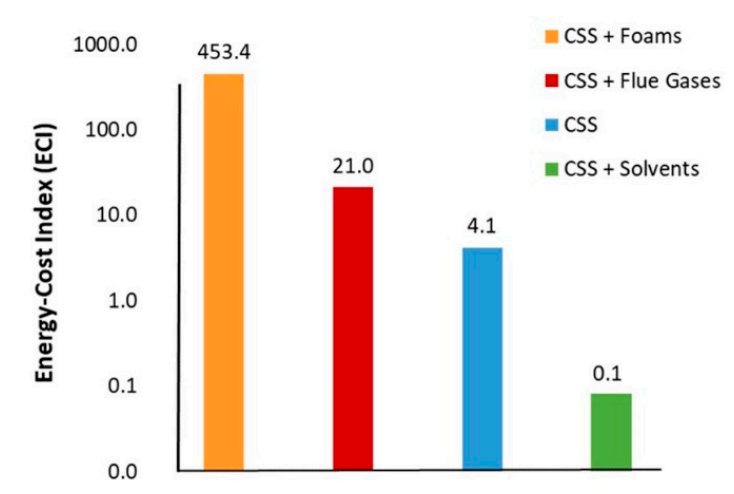

Figure 7. Energy cost index (ECI) of CSS vs. hybrid CSS methods evaluated during the sixth steam cycle. 


\section{Conclusions}

It is important to recognize that the performance of wells under CSS depends on multiple variables and that the efficiency of oil recovery decreases as the number of steam cycles increases. Even in the later stages of CSS, this recovery process can be economically attractive in high-oil-price environments. However, and regardless of the economics of CSS in later stages, the process can be energy inefficient.

The hybrid CSS methods represent alternative techniques to improve heavy oil recovery in mature wells. However, the use of solvents or nanoparticles is inefficient in terms of energy or costs based on the current state of the technology, respectively. Here, both methods performed better in the early stages of CSS (i.e., at higher oil saturations). On the contrary, hybrid CSS with flue gas or foams performed better in later stages of the process (during or after the sixth steam cycle). However, based on the ECI, CSS with foam outperformed $(E C I \approx 453)$ cyclic steam injection with flue gases $(E C I \approx 21)$, resulting in a more cost-effective and energy-efficient method compared with CSS with flue gases.

The proposed approach, based on a simplified economic and energy balance analysis, represents a fast screening method that has proved valuable in supporting management decision-making to allocate resources for laboratory and engineering studies to evaluate the most promising thermal EOR technologies to meet Colombia's energy needs.

Author Contributions: Conceptualization, E.M.; Methodology, L.O., L.G., R.P., C.B. and J.B.; Software, L.O., C.B., J.B. and J.S.; Validation, E.M. and R.P.; Formal Analysis, E.M., R.P. and J.S.; Writing-Original Draft Preparation, L.O. and L.G.; Writing-Review \& Editing, L.O. and E.M.

Funding: This research was funded by Ecopetrol S.A.; Instituto Colombiano del Petróleo and Universidad Industrial de Santander cooperation agreement [No. 5222395].

Acknowledgments: The authors would like to thank Universidad Industrial de Santander (Agreement No. 25), Instituto Colombiano del Petróleo (ICP), and Ecopetrol, S.A. for the permission to publish this paper.

Conflicts of Interest: The authors declare no conflict of interest. The funders had no role in the design of the study; in the collection, analyses, or interpretation of data; in the writing of the manuscript, and in the decision to publish the results.

\section{Abbreviations and Conversion Factors}

${ }^{\circ} \mathrm{C}$

${ }^{\circ} \mathrm{F}$

B/C

bbl

BOE

BTU

$\mathrm{CO}_{2}$

CAPEX

CSI

CSS

CSOR

$\mathrm{D}$

d

DNI

EE

ECI

$\mathrm{ft}^{3}$

$\mathrm{ft}$

FR

gal

J

$\mathrm{kg}$

$\mathrm{K}_{\mathrm{v}} / \mathrm{K}_{\mathrm{h}}$
Degrees Celsius, $1^{\circ} \mathrm{C}=33.8^{\circ} \mathrm{F}$

Degrees Fahrenheit

Benefit-cost ratio

Barrels

Barrel of oil equivalent; $1 \mathrm{BOE}=5.722 \times 10^{6} \mathrm{BTU}$

British thermal units, 1 BTU $=1055.56 \mathrm{~J}$

Carbon dioxide

Capital expenditure

Continuous steam injection

Cyclic steam injection

Cumulative steam/oil ratio

Darcy

Day

Direct normal irradiation

Energy efficiency index

Energy cost index

Cubic foot

Foot

Recovery factor

Gallon

Joule

Kilogram

Relation between vertical and horizontal permeability 


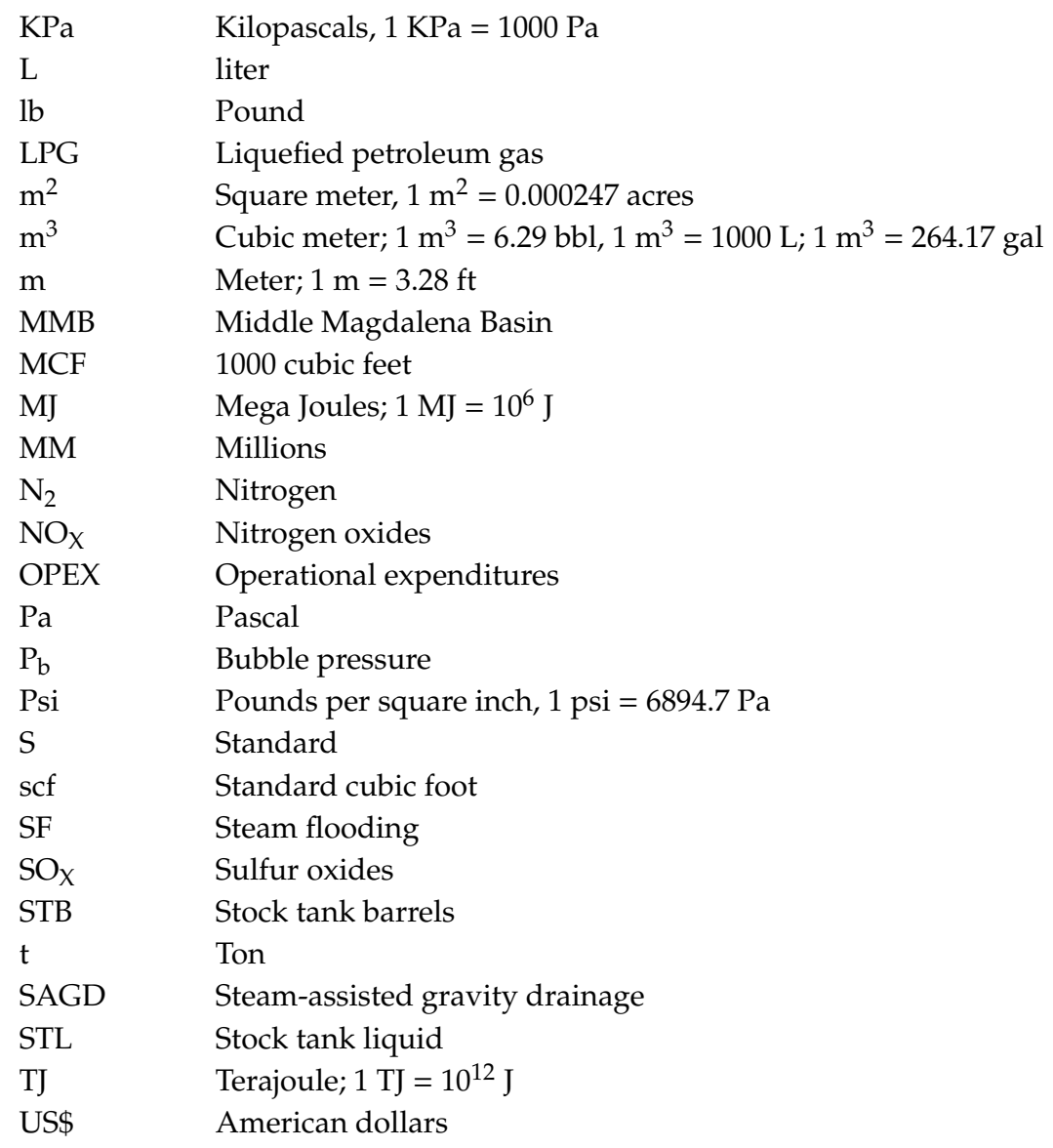

\section{References}

1. Alvarado, V.; Manrique, E. Enhanced oil recovery: An update review. Energies 2010, 3, 1529-1575. [CrossRef]

2. Koottungal, L. Survey: Miscible $\mathrm{CO}_{2}$ continues to eclipse steam in US EOR production-2014 worldwide EOR survey. Oil Gas J. 2014, 112, 78-91.

3. U.S. Energy Information Administration: Petroleum \& Other Liquids. Available online: https://www.eia. gov/petroleum/drilling/\#tabs-summary-2 (accessed on 18 April 2019).

4. Alvarez, J.; Han, S. Current Overview of Cyclic Steam Injection Process. J. Pet. Sci. Res. 2013, 2, $116-127$.

5. Bayestehparvin, B.; Farouq Ali, S.M.; Abedi, J. Solvent-Based and solvent-assisted recovery processes: State of the art. SPE Res. Eval. Eng. 2019, 22. [CrossRef]

6. Dong, X.; Liu, H.; Chen, Z.; Wu, K.; Lu, N.; Zhang, Q. Enhanced oil recovery techniques for heavy oil and oilsands reservoirs after steam injection. Appl. Energy 2019, 239, 1190-1211. [CrossRef]

7. Trigos, E.M.; Rueda, S.F.; Rodríguez, E.; Rivera de la Ossa, J.E.; Naranjo, C.E. Key strategies in the heat management for steamflooding projects, Teca Field Application. In Proceedings of the SPE Enhanced Oil Recovery Conference, Kuala Lumpur, Malaysia, 2-4 July 2013. [CrossRef]

8. Pang, W.; He, Z.; Wu, Q.; Hou, Q. EOR enhancement potential analysis for one oilfield. In Proceedings of the SPE Asia Pacific EOR Conference, Kuala Lumpur, Malaysia, 11-13 August 2015. [CrossRef]

9. Franco, F.; Useche, M.; Vargas, L. Workflows to Assist in Managing a Heavy Oil Field in the Middle Magdalena Basin, Colombia. In Proceedings of the SPE International Heavy Oil Conference and Exhibition, Kuwait City, Kuwait, 10-12 December 2018. [CrossRef]

10. Rodríguez, E.; Barrios, W.; Sandoval, R.; Santos, N.; Cortes, I. Numerical simulation for cyclic steam injection at santa clara field. C.T.F Cienc. Tecnol. Futuro 2008, 3, 107-128.

11. Mansarovar Energy: Technologies at Mansarovar Energy. Available online: http://www.mansarovar.com.co/ en/operaciones/cadena-de-valor/desarrollo (accessed on 19 April 2019). 
12. Pérez, R.; Sandoval, J.; Barbosa, C.; Delgadillo, C.; Trujillo, M.; Osma, L.; Bottet, J.; Garcia, L.; Rodríguez, H. Comparación de alternativas para mejora de la inyección cíclica de vapor mediante simulación numérica. Revista Fuentes 2018, 16, 91-108. (In Spanish) [CrossRef]

13. U.S. Energy Information Administration. Units \& Calculators-British Thermal Units (BTU). Available online: https://www.eia.gov/energyexplained/index.php?page=about_btu (accessed on 19 April 2019).

14. Farouq Ali, S.M. Heavy Oil Recovery: Principles, Importance, Status and Operation, Course Manual, Bogota, 19-22 August 2014. Available online: https://www.scribd.com/document/328623172/EOR-Course-Slides-byFarouq-Ali (accessed on 21 May 2019).

15. Agista, M.N.; Guo, K.; Yu, Z. A State-of-the-Art review of nanoparticles application in petroleum with a focus on enhanced oil recovery. Appl. Sci. 2018, 8, 871. [CrossRef]

16. Druetta, P.; Raffa, P.; Picchioni, F. Plenty of room at the bottom: Nanotechnology as solution to an old issue in enhanced oil recovery. Appl. Sci. 2018, 8, 2596. [CrossRef]

17. Nassar, N.N.; Hassan, A.; Pereira-Almao, P. Application of nanotechnology for heavy oil upgrading: Catalytic steam gasification/cracking of asphaltenes. Energy Fuels 2011, 25, 1566-1570. [CrossRef]

18. Shokrlu, Y.H.; Babadagli, T. Viscosity reduction of heavy oil/bitumen using micro and nano metal particles during aqueous and non-aqueous thermal applications. J. Pet. Sci. Eng. 2014, 119, 210-220. [CrossRef]

19. Clark, P.D.; Clarke, R.A.; Hyne, J.B.; Lesage, K.L. Studies on the effect of metal species on oil sands undergoing steam treatments. Aostra J. Res. 1990, 6, 53-64.

20. Shokrlu, Y.H.; Babadagli, T. In situ upgrading of heavy oil/bitumen during steam injection by use of metal nanoparticles: A study on in situ catalysis and catalyst transportation. SPE Reserv. Eval. Eng. 2013, 16, 333-344. [CrossRef]

21. Choi, S.U.S.; Eastman, J.A. Enhancing thermal conductivity of fluids with nanoparticles. In Proceedings of the ASME International Mechanical Engineering Congress \& Exposition, San Francisco, CA, USA, 12-17 November 1995; 1995; Volume 231, pp. 99-106.

22. Xuan, Y.; Li, Q. Heat Transfer enhancement of nanofluids. Int. J. Heat Fluid Flow 2000, 21, 58-64. [CrossRef]

23. Choi, S.U.S.; Zhang, Z.G.; Yu, W.; Lockwood, F.E.; Grulke, E.A. Anomalous thermal conductivity enhancement in nanotube suspensions. Appl. Phys. Lett. 2001, 79, 2252-2254. [CrossRef]

24. Mohammad, A.A.A.; Mamora, D.D. In-situ upgrading of heavy oil under steam injection with tetralin and catalyst. In Proceedings of the Internationsl Thermal Operations and Heavy Oil Symposium, Calgary, Canada, 20-23 October 2008. [CrossRef]

25. Franco, C.A.; Cardona, L.; Lopera, S.H.; Mejía, J.M.; Cortés, F.B. Heavy oil upgrading and enhanced recovery in a continuous steam injection process assisted by nanoparticulated catalysts. In Proceedings of the SPE Improved Oil Recovery Conference, Tulsa, OK, USA, 11-13 April 2016. [CrossRef]

26. Yi, S.; Babadagli, T.; Li, H.A. Use of nickel nanoparticles for promoting aquathermolysis reaction during cyclic steam stimulation. In Proceedings of the International Petroleum Technology Conference, Bangkok, Thailand, 14-16 November 2016. [CrossRef]

27. Alomair, O.; Alajmi, A. Experimental study for enhancing heavy oil recovery by nanofluid followed by steam flooding NFSF. In Proceedings of the SPE Heavy Oil Conference \& Exhibition, Kuwait City, Kuwait, 6-8 December 2016. [CrossRef]

28. Maity, S.K.; Ancheyta, J.; Marroquín, G. Catalytic aquathermolysis used for viscosity reduction of heavy crude oils a review. Energy Fuels 2010, 24, 2809-2816. [CrossRef]

29. Hamedi Shokrlu, Y. Enhancement of Heavy Oil/Bitumen Thermal Recovery Using Nano Metal Particles. Ph.D. Thesis, University of Alberta, Edmonton, Alberta, 2013.

30. Sigma-Aldrich (Merck). Nickel (II) Oxide: 637130-250G. Available online: https://www.sigmaaldrich.com/ catalog/product/aldrich/637130?lang=en\&region=CO (accessed on 20 April 2019).

31. Ahmadi, M.A.; Hasanvand, M.Z.; Shokrolahzadeh, S. Technical an economic study of flue gas injection in an Iranian oil field. Petroleum 2015, 1, 217-222. [CrossRef]

32. Zhdanov, S.A.; Amiyan, A.V.; Surguchev, L.M.; Castanier, L.M.; Hanssen, J.E. Application of foam for gas and water shut-off: Review of field experience. In Proceedings of the SPE European Petroleum Conference, Milan, Italy, 22-24 October 1996. [CrossRef] 
33. Delamaide, E.; Cuenca, A.; Chabert, M. State of the Art of the Steam Foam Process. In Proceedings of the SPE Latin America and Caribbean Heavy and Extra Heavy Oil Conference, Lima Peru, 19-20 October 2016. [CrossRef]

34. Petroleum Resources Management System (PRMS)—2018 Updates. Available online: https://www.spe.org/ en/industry/petroleum-resources-management-system-2018/ (accessed on 22 January 2019).

(C) 2019 by the authors. Licensee MDPI, Basel, Switzerland. This article is an open access article distributed under the terms and conditions of the Creative Commons Attribution (CC BY) license (http://creativecommons.org/licenses/by/4.0/). 